Portland State University

PDXScholar

6-1-2013

\title{
Use of Gender Aschematicity in the Reassessment of Gender Concepts
}

Ashley A. Ward

Portland State University

Follow this and additional works at: https://pdxscholar.library.pdx.edu/honorstheses

Let us know how access to this document benefits you.

\section{Recommended Citation}

Ward, Ashley A., "Use of Gender Aschematicity in the Reassessment of Gender Concepts" (2013).

University Honors Theses. Paper 34.

https://doi.org/10.15760/honors.36

This Thesis is brought to you for free and open access. It has been accepted for inclusion in University Honors Theses by an authorized administrator of PDXScholar. Please contact us if we can make this document more accessible: pdxscholar@pdx.edu. 
Use of Gender Aschematicity in the Reassessment of Gender Concepts

by

Ashley A. Ward

An undergraduate honors thesis submitted in partial fulfillment of the requirements for the degree of

Bachelor of Science

in

University Honors

and

Psychology

Thesis Adviser

Linda Gallahan

Portland State University 


\begin{abstract}
The purpose of this thesis is to reevaluate the binary constructs of sex and gender; and the biological and social influence these constructs have on males, females, and non-normative individuals. Throughout this examination, biological, specifically chromosomal and anatomical, differences between sexes will help foster a definition of sex. Psychological theories will then be examined, calculating the psychological and social factors surrounding gender. A reevaluation of gender constructs will shed light on previously held misconceptions about gender and help lay groundwork for non-normative gender acceptance in the future. Furthermore, the thesis will delve into gender aschematicity and potential benefits of gender aschematic concepts as a means of reevaluation of the gender constructs.
\end{abstract}




\section{Use of Gender Aschematicity in the Reassessment of Gender Concepts}

Our beliefs about gender are deeply rooted in our cultural ideals and have historically operated within a strict binary system that mandates women and men embody non-overlapping constructs of femininity or masculinity. In today's world, scripts surrounding gender create problems for individuals who may not subscribe to the strictly binary categories our world mandates. Binary definitions of sex and gender are too restrictive to properly represent the people being defined by them. Anyone finding themselves ambiguously gendered are marked as deviant by the gender "normative" members in a society who view women and men as distinctly different. As these non-normative perspectives expand our world view, we see more people challenge the conventional, and in some cases antiquated, roles of gender. Changes need to be made to our constructs of gender to better represent the actual population and to promote tolerance and equality among all people. This thesis will examine the constructs of gender in regard to their scholarly discourse and will apply cognitive aschematicity as a way to reassess the constructs and better represent the entirety of the population.

In order to examine gender and its influence as a cultural concept, this thesis will evaluate scholarship surrounding sex and gender. A scope of biological development will permit a view into structural differences/similarities among male, female, and intersexed bodies assessing the current definitions and parameters of sex. With these parameters in mind, we will delve into differing theories surrounding the sexes.

Next we'll explore the psychological aspects of current binary gender categories, and their implications on gender identity development, as a way to introduce a spectrum based gender system, one that moves beyond the rigid roles of masculinity-only for males and femininity-only

for females. Intersexed and transgendered populations may have difficulty finding where they 
belong in our society's rigid binary sex/gender system, albeit for differing reasons. This thesis will discuss the binary structure as well as masculine, feminine and other gender categories as a parallel to the previous analysis of biology. We will define and differentiate sex, gender, and gender identity through their theoretical histories.

With both nature and nurture investigated, we will discuss different developmental theories surrounding gender, starting with Freud, then, more modern theorists. This thesis will then move toward social constructions of gender with emphasis on gender schema theory to get a better grasp on the nature of our current categorizations. These distinctions will assist us in considering social implications of gender and how gender schemata affect individuals' lives, from daily interactions to lifespan development.

Furthermore, this thesis will compare gender schematic and gender aschematic tendencies. The analysis of discourses here will show that minimizing gender schematic tendencies, which are based on our current social constructions of gender, and promoting gender aschematic tendencies will help in promoting tolerance and understanding of individuals who do not subscribe to traditional gender roles. Additionally, it will help eliminate the need for the binary gender system we currently hold. By doing this, invisible populations, such as intersexed and transgendered individuals, will be less stigmatized.

Finally, we will look at the applications of gender aschematicity, the attempt to eliminate gender influence from one's perspectives, in other cognitive schema. We will observe gender aschematic individuals and how they might more easily form cognitive aschematic models among other schema. This observation will show that gender aschematic lifestyles promote equal 
or equitable relations across the entire human experience and assist in reassessing our gendered notions.

\section{Review of Scholarship}

To gain better knowledge and insight into sex and gender concepts, we must begin with a review of the literature or scholarship. While there are varying scholarly discourses, this thesis will delve into two primary sources of scholarly discussion as discussed in the introduction: a biological discourse and a psychological discourse. Following the psychological discourse, associated scholarship regarding social constructions of gender will allow supplementary perspectives of the topic. Review of the scholarly discourses will provide a historical reference of how sex and genders concepts work currently and offer insight for the discussion of how the discourses might move forward in the future.

\section{Biological Development}

Our understanding of sex and gender begins with our interpretations of human biological development. The sex of an individual is deemed "Either of the categories of male or female or the sum total of biological attributes on which this distinction is based within a species" (Coleman, 2009, p. 692). For humans, sex is the primary and most salient distinction used to categorize one another. We can identify a person's sex faster and with greater accuracy than we can their age, race, or any other known category (Hyde, 2005). Sex is such a prominent interest that we even seek out the sex of our infants before they are born. Gender and sex are concepts that rule our world.

The development of sex. Our sex is determined by a series of reproductive processes. Out of 23 pairs of chromosomes, the final pair comes together to determine which reproductive 
organs we will develop, thus determining our sex. Reproductive processes also determine which hormones we produce and at which levels (Wizemann \& Pardue, 2001). Our genetic makeup, or genotype, contributes to some of the physical phenotypic manifestations of our sexed characteristics. It determines development of muscle mass and fatty tissues, genitalia, such as ovaries or testes, and other sexed distinctions. Through pre- and postnatal environmental interactions, one's phenotype may demonstrate features inconsistent with one's genotype. For example, while one may have female reproductive anatomy, their phenotype may exhibit more masculine features, such as broader facial structures or increased body hair. While genetics produce a distinction between female and male anatomy, there is overlap of masculine and feminine physical characteristics (Fausto-Sterling, 2001). This overlap will be an important point of reference in our later discussion of gender development and social structures.

The existence of the dichotomous, non-overlapping, sex characteristics fuels discourse that examines binary sex regulations that place wholly male or wholly female archetypes as two opposing poles. Populations that vary from this dichotomy present a need for the construction of a gender spectrum system as opposed to solely binary gender and sex distinctions. This is especially true as we approach intersex populations who share a blend of masculine and feminine anatomy and transgendered populations who do not recognize their prescribed gender (Coleman, 2009).

Intersex development. What we know of intersex populations comes from our examination of the chromosomal disorders that create non-normative or ambiguous sexed bodies. These rare disorders are often manifested during prenatal development. In normative development, an XX pairing will produce a genetic female, while an XY pairing will produce a genetic male. Non-normative development can produce uncommon genetic combinations such as 
XXY, XYY, XYYY, and XO. These aneuploidic combinations, in which there are too few or too many chromosomes, create neither male nor female bodies, but instead, intersexed bodies with differing physical structures (Visootsak, 2009).

The aneuploidic chromosomal combination XXY, called Klinefelter's Syndrome, produces an individual who is biologically male but who appears to have feminine physical traits. The testes and penis are smaller in Klinefelter's persons, who also have sparse body hair, wider hips and fatty breast tissues. XXY individuals have been noted to suffer from learning disabilities (Lanfranco, 2004). These individuals are probably most easily recognized aneuploid due to their combination of visible female and male bodily characteristics. Other chromosomal combinations such as XYY, or in rarer cases XYYY, produce masculine bodies that are unusually tall in comparison to others. These persons, too, experience learning disabilities and lower intelligence on average. It is hypothesized that certain abnormal chromosomal compositions may contribute to differences in neural development (Visootsak, 2009). The aneuploidic XO chromosomal configuration, or Turner's Syndrome, is a malformation that keeps an individual from producing androgens and estrogens and, consequently, internal reproductive organs. Externally, these persons develop female structures and are generally raised as females (Sybert, 2004).

In biological terms, these intersexed populations are acknowledged in research, but not studied as extensively as normative populations. They are viewed as biological rarities and there has not been much research examining their physical or psychological development independently of "normal" developing bodies. Instead, intersexed individuals are described in terms of their deviation from normative male and female standards and are forced into the male only or female only roles of our social binary sex/gender system. Variations or ambiguity in sex 
are deemed as a problem in the human form, which doctors attempt to "fix" with gender reassignment, hormone injections and other medical procedures (Callahan, 2009). Parents often opt to have their intersexed children undergo hormone treatments or surgery to look or function in ways more consistent with our social standards or binary sex/gender categories. In the biological and medical worlds we still let social ideals of gender dictate how we approach nonmale and non-female sexes.

Physical development. In infancy, normative children develop at about the same rate. Males and females from birth through middle childhood develop senses and gain weight and height comparably. Females are believed to be slightly more advanced in their motor development, but few differences exist between the sexes in terms of physical development (Darrah, Senthilselvan, \& Magill-Evans, 2009). It is not until puberty that the sexes begin to differ in their physical development.

Beginning with puberty and continuing into early adulthood, we see physical changes that sharply delineate the sexes. Brain structures, including the pituitary gland, trigger organs such as the ovaries and testes to secrete gonadotrophic hormones throughout the body, activating the onset of puberty (Lerner \& Steinberg, 2009). Those hormones activate the development of sexually dimorphic, secondary sex characteristics that facilitate reproductive activities (e.g., finding a mate).

During puberty, both males and females gain weight and height as well as grow pubic and underarm hair. In addition, sexually dimorphic features develop which enhance the distinction between males and females. For males, puberty brings on increased muscle, growth of the penis and testicles, and the ability to ejaculate (Lerner \& Steinberg, 2009). In females, breast 
tissues grow and the hips widen. Menarche, the first menstrual period, marks the beginning of a female's reproductive capability, which lasts into her fifties (Al-Sahab, Ardern, Hamadeh, \& Tamim, 2010).

In adolescence, physical development varies between the sexes more than at any other time in the lifespan. After puberty has subsided, development begins to even out again. Important biological features such as health and longevity become based more on socio-cultural environmental factors, including lifestyle, and biology is less determinant of outcome. Growths and declines in physical and mental development continue until death and are relatively equal between men and women. One notable gendered difference in adulthood is the life expectancy in women, which is longer than in men on average (Older Americans, 2012). This is suspected to be caused by social factors and not due to biological factors. Some of these factors include: more risk taking among males than females, and female familiarity with doctors (during pregnancy or during feminine check-ups) increasing the likelihood of seeking needed medical help (Barford, Dorling, Smith, \& Shaw, 2006). Increases in autoimmune disease (affecting primarily women) are lessening the life expectancy gap between men and women (Whitacre, 2001).

Brain development. Brain, or neural, development is marked by a series of processes that help to generate a nervous system and shape and organize its structures throughout life. Starting in gestation, genes and environmental triggers go to work to create fetal brain tissues. The tissues will further divide and grow in complexity until cortical tissues (masses of neurons that make up the cortex) are present. The process of brain development during gestation, and resulting brain structures fail to differ between the sexes. 
Sexed-brain theory. From childhood through adult development, cognition and brain physiology discourses show varying stances on sexed-brain development. Ultimately, it is believed that female and male brains operate differently even though their neural structures do not differ.

Biologist Leonard Sax (2005) advocates for a sex differences platform wherein he posits that female and male brains have genetically programmed differences that affect daily interactions, problem solving, perceptions and a myriad of other life functions. In his analysis, the brain operates in distinct ways for men and women.

Sax presents a series of research articles to support his stance that male brains are more lateralized than female brains, meaning that functions may operate in specialized areas of the brain. Specialized areas communicate to other specialized areas as needed for the function. Lateralization is said to be powered by mid brain and more primitive structures of the brain for males. Conversely, it is believed that the cortical structures are used more than primitive structures in female than in male brains (Gur et al. 1999). Sax further notes that females do not have lateralization like males, but rather have integrated systems, where multiple areas of the brain work together during processing. According to the studies reviewed, brain function occurs in varying areas of the brain at once, rather than in only specialized areas.

There is so much that is still unknown about the brain that it is difficult to say exactly why sexed-brain differences are found in some studies. If male and female brains are made up of the same anatomy they should not function differently. Sax's argument seems to be a poor case for sex as the sole basis for brain difference, especially since he discounts social/cultural influences as a contributor. However, according to other research done by intelligence theorists 
Sternberg (1988) and Gardner (1983), social influence and intelligence variation seem more likely to cause brain differences than sex. It is clear that brains function differently, as this is seen throughout multiple discourses. However, whether or not, or to what extent, these differences are based on sex is unclear.

Intelligence-influenced brain theory. A more likely reason for brain differences between individuals is that we are using different types of intelligence. Intelligence theorists have differing opinions on the number and types of intelligence humans have, but it is generally agreed that there are more than one. Differing intelligences are influenced by the experiences and environment for each individual (e.g., artist's intellect is not the same as a mathematician's). As opposed to a singular intelligence, multiple types of intelligence better encompass the way people process information. While assessing intelligence types, theorists make little or no reference to sexed difference, which further deflates Sax's theory.

In his Triarchic Theory of Intelligence, psychologist Robert Sternberg (1988) posits that there are three types of intelligence: analytical, practical and creative. These three types of intelligence play on the strengths or weaknesses of one another. Everyone with normative brain development possesses the capacity for intelligence in all three areas, but to varying degrees.

In comparison, psychologist Howard Gardner (1983) claims there are as many as nine types of intelligence. As with Sternberg's theory, Gardner believes that humans vary in strength within different intelligences, but do not see that variation as a function of biological sex. For example, scientists may have more pronounced analytical abilities, athletes may exhibit stronger bodily-kinesthetic intelligence, and psychologists more refined interpersonal and intrapersonal intelligences. Consequently, scientists, athletes and psychologists will have different ways of 
processing their world experience regardless of gender. Male dominant or female dominate disciplines that require different intelligences may account for the brain function differences proposed by Sax. Differences seen in neural processing, are thus more heavily influenced by culture than they are by genetic sex differences.

The aptitude for varying types of intelligence is ingrained in us somewhat biologically, but intelligence is also shaped by environmental stimuli (Gardner, 1983). Experiences in school, culture, etc., where gendered stereotypes or gender roles are highly reinforced, change how children learn about gender and view males and females (Sax, 2005). It is more likely that brain lateralization and integration differences between males and females are based on the different socially determined functional needs of intelligence, rather than sex. However, because of our belief in sex differences as dichotomous, opposing and biologically based, researchers make the leap that the brain of a female receptionist and a male engineer differ because of their sex, rather than because of the types of intelligence they possess due to their differing environments.

Studies have shown that males and females within like-fields perform fairly equally; and that it is the treatment of women during their education that causes high rates of drop out and gender disparities among the sciences (Brush, 1991, p 416). Lack of incentives and obstacles within educational systems displace women (Felder, Felder, Mauney, Hamrin, \& Dietz, 1995) and this displacement may contribute to our ideas of sex-brain differences. Not only do we believe in and support sex differences, but we also further assist in maintaining the dichotomous constructs to the detriment of our society. This on its own is evidence that reassessing our sex and gender systems is necessary. 
The study of multiple intelligences and their influence on brain function is an unexplored area in Sax's sexed-brain discourses. More research is needed in both sexed-brain difference and intelligence-influenced brain difference in order to definitively support, refute or refine each stance.

The intersexed and transgendered brain. If we followed Sax's sexed-brain stance and agreed that in fact male and female brains did operate differently, then what might develop among non-normative sexes? Transgendered individuals, whose gender identity is inconsistent with their biological or assigned sex, and intersexed individuals, who vary from biological norms, cause problems with Sax's argument. Under his premise, these populations should show a different type of brain function than normative male and female populations. If functionality between the male and female brains is different, then we should expect to find additional variation among non-normative sexes.

Little research has been done to examine developmental differences in the brain between normative and non-normative (i.e., intersexed, transgendered) populations. If male and female brains develop as differently as Sax suggests, then research into intersex and transgender brain function may broaden our understanding of these purported sexed differences. Whether sex differences occur as a function of brain development, cultural experience, or some other unmeasured factor, these unexamined populations could hold interesting information for the biological, psychological and neurological sciences.

Neuroscientist Simon LeVay's research on gay populations provides the closest example of research regarding brain function in non-normative populations. LeVay (2011) published research suggesting that gay males' brains differed from straight males' brains and were more 
similar to females in brain function. Areas at the base of the brain were examined for specific structures that were believed to vary in size between the sexes. LeVay believed that these size differences would show distinctions between the gay and the non-gay. His findings on gay brain function have not been replicated, and his conclusions have been refuted by others in the field (Sax, 2005) for their lack of accuracy. It is currently held that no differences are found between straight and gay brains.

Despite its limitations, LeVay's research is one of the closest examples we have regarding non-normative populations. More research examining intersexed and transgendered populations could provide knowledge into areas where gender has previously distorted (as seen in the discourse between sexed-brain and intelligence-influenced theory) scholarly interpretation. Because gender is a much more fluid concept among LGBT populations, there is a chance to learn more about people, without strict confines of gendered categories. Since the variety in the human experience is not solely based on normative experience, these rarer populations need to be examined to incorporate the diversity of intersexed and transgendered lives into the scope of human life (Callahan, 2009).

\section{Psychological Perspectives of Gender Identity Development}

In the last section, we focused on the biological construct of sex, the sum total of biological attributes on which maleness and femaleness are based within a species, and biological discourses surrounding the brain. In this section, we turn our attention to the development of social constructs, such as gender identity and gender role.

Gender is considered the behavioral, social and cultural attributes associated with one's sex (Coleman, 2009, p. 309). Gender is the lens through which we articulate masculine, 
feminine, and androgynous categories. From gender, further social designations arise, which are utilized to linguistically articulate concepts of gender. These include gender identity and gender role. Gender identity is the degree to which one psychologically identifies with one's biological sex. Gender role is the degree to which one subscribes to the social constructs of masculinity and femininity.

In our discussion of gender, we move away from some of the physical manifestations of sex and move toward the mental aspects of gender development including the influence of one's given sex and gender identity. Less focused on the physical body, theorists in the psychological field delve into the mental faculties that shape our perceptions of gender. This discourse becomes more subjective in nature as theorists are working with the increasingly subjective experiences of individuals and social influences on our ideas of gender.

In discussions of biological discourse, we examined the distinct categories of sex: male, female, and intersex. In discussions of psychological discourse, we will examine masculine and feminine populations, as well as transgender populations. These categories of gender are not as distinct from one another as our categories for the sexes, neither are they the only three gender choices.

Intersexed individuals, those who are not biologically male specific or female specific in sex, are represented in all gender categories. Similarly transgendered individuals, those whose gender identity does not match their assigned sex, can be of any sex. It is important not to confuse intersex and transgender as alternating terms (like one might with male sex and male gender) but to understand that sex and gender, in this discourse, are no longer mutually exclusive. This further illustrates the challenge we face when attempting to categorize 
individuals within the binary sex-gender system: those who do not easily "fit" into categories of male/female, masculine/feminine are collapsed into an "other" category that represents deviancy from the norm (e.g., non-heterosexuality).

In psychological views, the male gender are those who agree with the physical, mental, and behavioral standards socially associated with masculinity. Female gender follows the same standards with regard to femininity. Transgendered individuals are people born and identified as a specific sex; however, they do not identifying with the sex assignment or they do not agree with associated gender. Transgendered persons may develop an identity inconsistent with the gender others perceive them as (e.g., a member of the female sex that identifies with the masculine gender), or they may develop an identity that represents a mix of the genders, no gender, an inclusive gender, or something entirely different. The transgendered experience is very specialized and dependent on the individuals' feelings surrounding sex and gender, and their interaction. Gender is very much based on experience and one's culture as opposed to the biological defining features of sex.

Psychodynamic theories. With definitions of gender in mind, we will discuss the psychodynamic discourse, containing two primary platforms, and continue into discourse by more contemporary theorists. The two platforms mentioned are the phallocentric view, a malecentered perspective of gender development, and the gynocentric view, a female-centered perspective of gender development. Both views describe male and female development; with differing emphases on the roles of the phallus and power (phallocentric) and the role of the mother (gynocentric).The theories build important discourses for later psychological theory. 
Phallocentrism. The phallocentric view of psychodynamic theory was first articulated in 1905 by neurologist and psychoanalyst Sigmund Freud in his theory on sexuality (Freud, 1962). This view focuses on the value and power of the phallus to gender identity development. Freud explains how children come to identify as male or female and explore their sexuality through a series of psychosexual stages. At each stage, children derive pleasure from a specific erogenous zone, or the bodily source of physical or psychical pleasure. Fixation on this erogenous zone may occur if the child does not adequately progress to the next stage of development. Such fixations are typically manifested in personality characteristics during adulthood.

For both sexes, attachment to the mother begins in infancy during the Oral Stage, the first of Freud's stages of psychosexual development, as infants derive pleasure through sucking during breastfeeding and through other oral stimulation. In the Anal Stage, children derive pleasure from elimination. In the third psychosexual stage, the Phallic Stage, children discover a sense of pleasure from their genitals. It is at this stage when children pass through what Freud referred to as the Oedipal Complex, a highlight of Freud's work, at which time the mother becomes an object of sexual desire for boys.

As they pass through the phallic stage, boys first attempt to be like the mother, thinking that they will be close to her as a result. They, then, develop a sense of_competition with the father for their mother's affections. Realizing that fathers have and maintain power superior to women, boys equate the male as an authority. Boys then come to associate male power with having a penis (the phallus) and develop an understanding that maleness equals superiority. The father then becomes a force to avoid, in that they believe that competition for power or affections of the mother may result in punishment, including potential castration of the phallus and 
consequent loss of power. As a result, boys abandon their feelings for the mother and associate with and learn from the father.

Girls, realize that their phallus (the clitoris) is less powerful than that of the male phallus and develop "penis envy." They then create competition with the mother for the father's affections hoping to obtain power through their male parent by bearing a male child. Girls eventually discover that they cannot obtain the phallus this way and re-align with the mother in an attempt to save the relationship (Freud, 1962). Freud's contemporary, psychotherapist Carl Jung (1915), would call this development in females the Electra Complex, the name adapted from the Greek myth of Agamemnon (Coleman, 2009). Contemporaries Jung and Freud debated the validity of the Electra complex, Freud believing it to be a contradiction of his own theory (Freud, 1962).

Jung's theory differs from Freud's in his belief that development was not sexually based, but instead that humans could be motivated in other ways. Jung proposes that our sense of gender was governed by subconscious archetypes. He proposes that two primary archetypes, the anima, or the conscious representation of femininity in males, and the animus, or the unconscious representation of masculinity in-females, govern identity development (Jung, 1915). Jung's stance on gender development is an early glimpse into gender spectrum possibilities, presenting that both men and women have opposing gendered characteristics that shape their personalities. Overlap of masculinity and femininity will be important in later social learning theories where feminist and other perspectives examine more complete populations, including intersexed and transgendered individuals, within sex and gender. 
Neo-Freudian psychologists have adapted Freud's views from a sexual and biological basis towards a more socio-cultural view. Psychologist Clara Thompson (1953), following in Freud's wake, adds that the Oedipal Complex is more a result of social than of biological exposure. Children observing the social hierarchies of power and privilege see a source of power in the phallus as Freud discussed. Their gender is based not in the biological possession of the phallus but, instead, in their relative social value. Thompson (1953) asserts that children desire to be valuable in their society and to hold social standing as the male population does. In Thompson's adaptation, psychology gains precious insight into biological and cultural influence working together more so than in previous Freudian theories. Thompson and Jung provide key facets for later feminist perspectives on psychosexual development, as both theorists delve into aspects of the female psyche that Freud had not.

Erik Erikson (1980), a German-American psychoanalyst, would later develop a stage theory based on Freud's work. Erikson proposed eight life stages that focused on social crises. Though he agreed with Freud's theoretical framework, he believed that children grow up with social influence rather than sexual influence. Instead of facing a psycho-sexual conflict, in each of Erikson's stages, an individual must confront a psycho-social crisis, such as trust v. mistrust, autonomy v. shame and doubt, initiative v. guilt, and others. Erikson's stages reflected the biological and psycho-sexual challenges presented in Freud's work, but on the whole, his theory focuses on the outcome of those challenges, including a sort of fixation he called "rumination" or the development of a virtue (Erikson, 1980).

Erikson's perspective on child development similarly aligned with Thompson in that children attempt to find their place in the social hierarchy. As children develop into their gender, they seek to find their power through their relationships with others. Their perceptions and 
feelings influence their understanding of the world. Additionally, Erikson (1964) proposed that reserved introverted "feminine" behaviors were a consequence of females' internal genitalia, whereas, assertive extroverted "masculine" behaviors were attributable to males' external genitalia. This associates biological and social development. As boys and girls observe their bodies, the physical nature of their genitals influences their self-image and thus their personality and behaviors (Erikson, 1964).

A key point in Erikson's work, not seen in Freud's work, is the examination of development of adults. While Freud's theory of development ends at adolescence, at which point he believed adult personality to be fully formed, Erikson (1978) realized that development continued into adult life and into old age. His stage theory presents the particular challenges of the adult life through death, broadening the knowledge base of developmental psychology. Previous theorists, like Freud, only examined development until adolescent stages. Erikson (1980) discusses gender throughout his theory of childhood development. This is expressed far less in adult development, indicating that either gender is ingrained in childhood and does not change or that male and females become more similar/androgynous in adulthood.

Theorists who embrace the phallocentric perspective give attention to male psychosexual identity development and emphasize the role of the phallus. While their theories incorporate female development, their analyses leave much to be desired. This can be, in part, attributed to the mostly male population of theorists in this area of thought. As more female theorists are introduced, other perspectives will supplant Freud's phallocentric view, providing a more equitable voice of the scholarship. 
Gynocentrism. Following Freud's view of gender identity development, we see an emergence of psychoanalytic theories supporting a more female, or what was later called, gynocentric view, the ideal that femininity, as demonstrated by the mother, influences children's development throughout life. Theorists of the gynocentric perspective believe, like Freud and others, that children begin life with interest in the mother. However, unlike Freud, they value the psycho-social over the psycho-sexual arguments.

Following Freud's male-centered theory came psychoanalytic theorist Karen Horney. A student of Freud's, she adapted the psycho-sexual model and presented the idea of socio-cultural gender development. Not unlike Thompson, Horney's theory further illuminates the female desire for power and social standing usually awarded to men (Horney, 1939). Horney called this "penis envy." She also believed that men would experience envy toward females for their capacity to bear children, and thus added "womb envy" (Paris, 1994). These two contrary terms demonstrate Horney's stance for equally able and equally flawed male and female bodies, with each gender desiring the strengths of the other. At this point, male strength is based on socially influenced factors such as power. Female strength still lingers in the biological realm in their physical capacity of child bearing. Horney's addition to the phallocentric perspective was incentive for further work in this area.

Helene Deutsch (1944), an Austrian-American psychoanalyst and follower of Freud, is one of the first psychoanalysts to specialize in female development. Though her ideas greatly align with that of Freud and the Oedipal Complex, her focus on women places her into the gynocentric perspective. Her writings consisted of several volumes describing the developmental processes of women from childhood into adulthood and incorporated different roles women adopted. Deutsch posits that the Oedipal Complex is more prevalent in mother-daughter 
relationships than in father-son relationships. Though a daughter's gender matches her mother, she desires to distinguish herself and obtain autonomy from her same-sex parent. Sons do not have such an intense reaction to the father in Deutsch's view because boys must independently learn about maleness which attributes to their extroverted behaviors.

According to Deutsch, further development of gender comes from the two primary roles that women hold: mother and lover. Children identify with one of these roles, choosing which fits their needs for development. Boys value of women as lovers. Girls accept the care giving role. Children develop their self-identity around their perception of women, growing to meet the female role best suited for them. Boys disregard the mother role and accept the lover role of women, in order to better separate from his mother and develop his own identity. Girls accept the nurturing mother role; however, the sexualized role creates a predicament: the two feminine roles clash, making it difficult for the daughter to find separation from her mother.

Another theorist following the Freudian model of gender development is Nancy Chodorow, a psychoanalyst and sociologist. Chodorow, like many others of the gynocentric perspective, believed that gender development was based on the cultural experience of children and centered on the mother. Chodorow suggests that male children are encouraged to find autonomous separation, or differentiation from the mother figure, whereas female children are encouraged to find union, or affiliation with the mother. Girls can more easily identify similarities between themselves and their mothers and are, therefore, more easily able to develop an idea of what it is to be female (Chodorow, 1978).

Boys, however, separate from the mother figure and must discover what it means to be male. In their autonomous experiences, boys learn to affiliate with their father (with whom they 
are physically alike) to learn male roles. Girls find it easier to relate to the mother, who has been a lifelong influence. However boys, given less access to their fathers than to their mothers, experience greater difficulty learning how to be male. Boys must learn what it is to be male by observing both the mother and father. By observing the mother and relying on what is not motherly hence, not-female, boys then have a guideline for maleness. Observation of the father, of male behavior, and access to male socialization helps shape male identity. Chodorow believes this leads to independent male dispositions that are marked by dissimilarities to femininity.

Chodorow's work places the theoretical structure of gender identity and development at interesting crossroads. Gynocentrists, including Chodorow, emphasize the influence of the mother, a female, on children's development of gender concepts, building onto feminist perspectives. Investigating the socio-cultural elements of mother-child influence, Chodorow proposes that gendered differences are based on gendered socialization. While discounting a biological basis for gender identity development, she observed numerous instances of gendered differences in parenting behavior. For example, she found that mothers hold their sons facing outward and their daughters facing inward, suggesting that this and other similar practices promoted, independence in boys and dependence in girls, respectively, and had implications for gender role identity development (Chodorow, 1989). She concluded that one's access to power and privilege is dependent upon their cultural fostering.

Chodorow is often seen as the mother or leader of feminism in psychoanalysis (Chelser, 1995). Chodorow's theory was no doubt influenced by emerging feminist discourse and social action which encompassed her work and publication (Gamble, 2001). Her stance on gendered imbalance would allow future feminist theorists to address not just individual gender 
development but social gender inequalities. Chodorow further allowed feminist views to be included in the psychological discourse.

Psychological perspectives give us insight into behavior and social interaction that biological perspectives cannot. Phallocentric and gynocentric psychological views provide an important foundation for the discourse on social development and gender. Even so, both views still dichotomize sex and gender into male or female with no attention given to non-normative populations. The phallocentric platform consisting of mostly male theorists unsurprisingly reinforces the importance of the male and the phallus. The gynocentric platform inserts female perspective and allow for diversity in the Freudian model. As this thesis approaches social learning theory, opposition to the Freudian model will further illuminate new perspective in gender inequalities.

Social learning theories. Social learning theories look at the influence of social situations on cognition and behavior. Not unlike gynocentric theorists, social learning theorists believe that development is based in social interactions and social context. This means that people, starting in childhood, learn behaviors by observing others and imitating their behaviors (Ormrod, 1990). We will examine how this applies to gender a bit later.

Social learning theories arose from behaviorist movements in psychology started by John B. Watson (1929). Important theorists to the school of behaviorism, such as Watson and later theorist B. F. Skinner (1938), believed that they could observe animals and humans in order to predict and control behaviors. Both men set out to observe outwardly visible behaviors and manipulate the environment in which those behaviors occurred. In this way they could shape the social context that behaviors took place in and thus shape the behaviors exhibited. The 
behaviorist model made it easy for theorists like Albert Bandura to step in and link social factors and human development, creating the social learning theory platform.

Bandura (1969) explains that models are pertinent sources for learning or modifying behaviors. The three models he discusses are the verbal instruction model, the live model, and the symbolic model. Each of these models operates in ways that influence the development of one's gender. In the verbal instruction model, a person is instructed in detail how to behave. This can be in a clinical setting or in parenting, schools and other environments. Verbal instruction models influence children's ideas of gender and gender identity if adults allow gendered information or bias to enter the model. The live model consists of a live example, usually a person, who demonstrates a behavior physically. The participant or learner then imitates the behavior. This too is used in schools or in parenting, as well as many other environments. The live model, like the verbal instruction model, can influence children's ideas of gender if the live model holds gender bias or gender stereotype. The symbolic model involves fictional presentations of behavior, such as characters in a play or movie. In developing children, models are most frequently other family members, teachers and neighbors (Bronfenbrenner, 1979), but currently, media is a growing influence, especially in regard to gender. Images portrayed in media or other symbolic models may include sexualized imagery, gender stereotypes and other examples of gender differentiated material.

Through Bandura's models and the processes described by social learning theory, children learn about their sex and gender as they are exposed to gendered behavior. Children imitate the models of gender, which we call "gender roles" or the behaviors, attitudes and traits associated with being male or female (Zucker \& Bradley, 1995), which are constructed along the dimensions of masculinity and femininity. Within our binary gender system, we do not currently 
have a cultural standard for non-normative gender roles. Transgendered populations are generally required to choose between male and female gender roles. Transgendered development is still not discussed at this point in the discourse.

Children learn their gender roles by direct instruction from adults of the same gender (live model), hearing expectations from parents and other adult figures (verbal instruction model), and observing certain media (symbolic model). They then imitate their perceptions of gender based on the social context in which they made their observation (Bandura, 1969; Bronfenbrenner, 1979). Parents and other adults in a child's life reinforce "correct" imitations with praise or with environmental stimulus, such as gendered toys. Reinforcement of gender appropriate behaviors helps solidify one's gender identity. This reinforcement stems from those closest to us, but also extends down from institutional and cultural systems across our lifespan.

Cognitive developmental theories. Gender roles as we learn them are salient and powerful, influencing our behaviors and experiences throughout the lifespan. Unlike their predecessors, the behaviorists, cognitive developmentalists do not believe that humans are passive machines prey to whatever their environment dictates. Instead, they are capable of interacting with and shaping their environment and how they do so depends on their experience and maturation (Piaget, 1971).

In his cognitive developmental theory, Jean Piaget (1971) asserts that individuals go through stages of cognitive development from birth through early adulthood. At each stage, children develop new cognitive abilities through experience and maturation. The stages are sequential, roughly universal, and progress in the same way for females and males across cultures. Cognitive development progresses through two processes, assimilation and 
accommodation. Assimilation occurs when a child learns new information that aligns with what they already know. This new information fits their existing schema, or mental framework, and is thus assimilated into their existing schema for that topic. Accommodation occurs when the child must change their schema to include new information that does not match their current knowledge (Piaget, 1971).

Psychologist Lawrence Kohlberg (1969) applied Piaget's model to gender, describing how children acquire an understanding of gender through schema development, much as they do when they learn about anything for the first time. For example, a child may have an existing schema for "dog" based on their limited experience with a single breed. When the child sees a new type of dog, they may not recognize the animal because it fails to match the qualities of "dogness" in their existing schema. They may fail to assimilate the information associated with this new animal. Following later cues from the environment, the child may adjust their schema for "dogs" to include the new example, thereby accommodating the information. If they see another animal for the first time, perhaps a deer, which shares some dog-like features, they will have to build a new schema to separate dogs and deer. The schema for dogs and deer, however, will be within an "animal" schema for the child. Similarly, with gender schema, children observe male and female behaviors and organize information associated with either gender into its correct category. Gender cues and novel information will go through these processes of assimilation and accommodation.

Both Piaget and Kohlberg believe children's concepts of gender are formed by ages three or four, when they achieve what is known as "gender constancy," the understanding that one's sex is immutable. Children then begin to label male and female specific objects, features, and activities, and apply those labels to others. Once a child begins this process, their concept of their 
own gender strengthens. Most children will then select activities and objects associated with their own gender only and may play with more children of their own gender for some time (Kohlberg, 1987).

Cognitive developmental theory allows for an understanding of transgendered identity development for the first time in our theoretical evolution. While the theory does not specifically address transgendered individuals, all persons within the scope of this theory develop their concepts of gender, and thus possibly their own gender identity, based on active interaction with their environment. If their social interactions expose them to non-normative genders, that information is then incorporated into their notions of gender and becomes a foundation for their own gender identity development.

The theory also allows intersexuals to adapt their ideas surrounding gender as well. Ambiguous bodily structures may leave intersexuals outside of male or female domains of sex, making gender identity difficult. However, within cognitive development theory, intersexuals can challenge the societal standards of the binary system of gender to influence their own life experience.

Individuals who experience an ambiguous or non-normative gender (transgender) or an ambiguous or non-normative sexual anatomy (intersexual) may reject social standards and gender roles for their assigned gender once they reach the final stage of cognitive development, formal operations (Piaget, 1971). Once the formal operational stage is reached, an individual is cognitively available to think critically about abstract concepts such as social gender constructs. This can occur as early as adolescence, but we are more adept around the age of twenty-five, when our frontal lobe has fully developed (Giedd et al., 1999). 
Gender schema theory. Born from the framework of Piaget's cognitive development theory and previous social learning theories is gender schema theory. This theoretical view, as introduced by psychologist and feminist Sandra Bem, focuses on socio-cultural influences on gender role identity development. Piaget's concept of schemes, or schemata, are the mental recipes or schematics for our knowledge of how things work. The psychological world would adopt the verbiage "schema," meaning "shape" in Greek (Coleman, 2009). Gender schema theory examines the development of schema for gender.

Bem (1981) posits that gender schema are shaped by the ease or difficulty of gendered information to be assimilated. The degree to which one assimilates masculine or feminine information is based on their exposure to gender-related information. Exposure to gendered information may give children rigid schemas surrounding what is masculine and what is feminine. However, if children are exposed to enough gender neutral information, they may build cognitively fluid or aschematic perceptions surrounding gender. Bem calls this process sex typing, where individuals' biological sex, socialized gender and expected gender roles reinforce individuals' notions of gender. A sex-typed individual, one who holds very rigid and dichotomous views of the roles appropriate for males and females, best assimilates gendered information corresponding to their own gender. Sex-reversed individuals, those whose gender role corresponds to that of the other gender, best assimilate information corresponding to that gender rather than their own. Androgynous persons, those who have characteristics of both genders, can more easily assimilate information regarding masculinity and femininity. Gender aschematic children, those who have fluidity of gendered ideas, have the propensity of recognizing variation within gender (e.g., that women potentially vary more from other women 
than they do from men). Additionally, gender aschematic children may maintain gender neutral or androgynous ideas.

An important distinction for Bem is that androgyny maintains the ideals of "maleness" and "femaleness." This concept maintains the binary gender system, whereas her idea of gender aschematicity implies transcending the binary gendered system. Later theorists would build from Bem's theory and create non-binary gender spectrums that allow for a continuum between masculine and feminine traits, or gender categories separate from male and female (FaustoSterling, 2000).

Unfortunately once the premise of this theory was supported, studies surrounding cognition and gender schema were not furthered. Research into aschematic child rearing would vastly add to the theory. Later in this thesis, we will examine aschematic models of gender and how cognitive processes involved in building schema. Additionally we will look into the applications for other non-gendered schematic fluidity as aschematic models reduce sex-typing and other cross-schema "typing."

Gender schema theory discourse acknowledges that the concept of gender roles is malleable. They vary as a function of a society's or culture's definitions of what roles are suitable for women and men in that society/culture. Therefore, we must also explore how gender is constructed.

\section{Social Constructions of Gender}

Gender is a term derived from a cultural reflection of sexed bodies and how they operate in a societal context. Because human nature enjoys categorization, populations together create categorizations for males and females. Without culture, we would not have concepts of gender. 
The social construction of gender theory, or social constructionism, focuses on the varying aspects of how gender is created by the social body and how it is maintained by those in power. This theory has grown in popularity among psychological, sociological and anthropological fields where researchers are examining social systems.

In its simplest form, social construction of gender is the process by which a society assigns value to the roles women and men play in a society and how it rewards and punishes its members according to how they conform or contradict those roles. In the binary system, these roles are distinct and separate the two genders. However, males and female are more similar than different and show more variation within gender than seen when compared to one another (Carothers, 2013).

Social constructionists Hare-Mustin and Marecek (1990) state that gendered meaning is created mostly by males. Males in power dictate the knowledge base for their definitions of gender and then pass the knowledge and definitions to others as "fact." This knowledge and concomitant definitions are based from our beliefs in the biological roots of sex that have been used to explain social differences between the sexes. For example, in hunter-gatherer societies men have been predominately hunters and women have been predominately gatherers. This role difference may help to explain differences between the sexes in terms of their cognitive processing, such that women employ fine-detail oriented mental processing while men employ gross-detail mental processing. In hunter-gatherer societies, females stayed with the community because of their ability to feed infants. This translated to nurturing of children and other members of the community as a female role. Since males do not have the biological capacity to feed infants, they assumed the role of hunter, which was later translated to their role as providers. The point here is one of scope. Do males have muscles and supposedly defined gross detail 
orientation because of their sex? Or are these a result of the social demands of the societies in which they lived? The answer is both. Similarly, are females superior in their fine motor coordination because of their sex, or because of the social structure of hunter-gathering that dictates women pick berries? Men and women evolve with these differences in part, because of their sex, but they have also evolved that way due to social standards placed on the different genders. Such social standards have been enacted over the generations of evolution of our species.

Nature is not without nurture and vice versa. If females in hunter gatherer societies had been demanded to swim to the bottom of a swimming hole to collect a food resource, they would have evolved with a sex difference in their lungs. This sexed difference would not be present without first there being a social demand. As we progress from industrial societies that require less specialization of abilities, our sexes may grow more androgynous since the biological need for sexed differences will have decreased. It is too soon to say. However, we must always examine scope, from its smallest impact on an individual, to the vast impact on all people across our timeline (Bronfenbrenner, 1979).

While biological distinctions between sexes were necessary at one point in history, they have continued to hold power in more modern times. Males have maintained higher status than women and have used this power as a way of constructing meaning. Because males are in power, superior male insight is passed down as truth. Social construction thus becomes social consensus.

Many issues arise from the social construction of gender. For one, gender stereotypes promote value of one gender over another. In Western, patriarchal cultures, we value the male over the female. This is demonstrated in our media, job markets, in the theories examined in this 
paper, and even in our use of generalized pronouns. We utilize language to make female perspectives inferior, so much so, that women who desire the power and privilege ascribed to males must sometimes side with male perspectives, further diminishing female perspectives and, as a consequence, women. Their agreement with the male perspective, at the cost of other women, offers a chance of equality and power for the individual, but often mimics the existing power dynamic. By aligning with only one perspective we eliminate the variety that exists in our world and silence voices that may have powerful insight to our social structure.

Non-normative populations, like today's "female" population, are pushed aside and given less power and privilege. When non-normative perspectives are expressed, they are discounted in favor of those expressed by those in power. The greater diversity of voices that are heard, the greater the chances are of power structures shifting. While females are not as powerful as males, they are more powerful than non-normative genders. In the existing binary system of gender, transgendered and intersexed individuals have very little voice adding to their social struggles.

Despite our awareness and understanding of these dynamics, restructuring an entire society is difficult. In American society, we still have deep-seated issues of race extending from slavery which ended nearly 150 years ago (Stevens, 1995). Even with the increase in liberal attitudes it would take a long time to enact change regarding gender equality. Such changes could help us eliminate gendered stereotype, and provide an equitable and safe domain for nonnormative genders within our social sphere. What makes this gender reform so difficult? As with most issues, lack of voice is a big contributor to gender inequalities. 
As pointed out earlier, the topics we examine scientifically are largely misconstrued by the scope of what is being examined. If biological research finds that there is a difference between the sexes, that difference will be defined as a division between the sexes, even if there is more overlap than difference involved. Generalized divisions are then placed on the entire population without proper representation of the actual difference found.

Conversely, biological discourses argue that sexed difference is based on biology, and offer very little input about social influence. Meanwhile socio-cultural views argue that gender is socially based with little reflection on biological influences. This is not to say that the discourses are false in their presentations, but they do overlook the scope of sex and gender within biological and cultural realms. Social constructions of gender would not exist without a dichotomous biological structure. To clarify, biology is not without social influence and social theories are not without biological basis.

Invisible populations: Intersex to transgenderism and beyond. Before scholarship on the social construction of gender, intersexed and transgendered populations were not well represented in our theoretical discourse. This is due to limited exposure, rarity of these populations, and lack of power in the sex/gender binary hierarchy.

Intersexuals who have ambiguous sex and transgendered individuals who do not identify with their given gender are very interesting populations to examine within the scope of gender construction. Because of the norms held by patriarchy, these individuals grow up with much confusion surrounding who they are and where they might fit in society. Intersexed individuals are sometimes raised by their parents as a gender different from that which the individual identifies. This may cause many problems, especially for adolescents who are learning about 
sexuality (ISNA, 2012). Some parents may even permit their intersexed infant to undergo surgery to "correct" their genitals, thus assigning a sex. This process may cause the child physical pain as they grow, but even greater psychological pain if the child fails to later identify with the gender associated with that sex. Intersexuals face possibilities of confusion and shame surrounding their bodies. These issues arise because of the social construct of "normative" sex and gender. Our current system of binary male and female sexes displaces intersexuals. Even the word "normative" assumes that intersexuality is not a natural occurrence.

Transgendered individuals face similar turmoil. These individuals who are labeled one gender but believe themselves to be the other gender, spend a lot of time struggling with identity. Since gender roles are socially constructed, and our society recognizes only two genders currently, transgendered persons have to battle the structure of our system to find their own identity. Frequently their chosen identity does not fit within male-only or female-only realms.

Transgendered populations still face a lot of variety surrounding their language and terminology. Since no standard has been agreed upon, there is much debate over the language used to identify such individuals. Some transgendered individuals may identify as one sex and attempt to transition to their desired gender either through appearance changes, including cosmetic surgery, representing the other sex. Their desire for this change is still rooted in socially constructed ideals created by the normative population. If a transgendered person is transitioning to a female body, they are bound by the standards of normative femininity. Transsexuals (transgendered persons who undergo gender-corrective surgeries) may still not be happy with their bodies if they feel they are neither male nor female, or that they are both genders simultaneously, because society does not have such designation. 


\section{Discussion}

Social and biological development theorists have been clashing for decades in regard to how humans grow within their sex and develop their gender. Biologists claim that our gender is determined by our biological sex and some discount social influence. Social development theorists focus on the social and psychological factors that shape and change us. Though we may have an assigned sex at birth, it is social encounters that determine what we learn about gender, the ideals about gender we hold as a community, and how we interact with others based on those shared ideals. Both perspectives are important in human development.

Biological discourse critique. The biological discourse maintains the idea that sex differences are expressed in biologically distinct and separate ways. Sexed distinctions are represented in the body through genes, hormones, sexual dimorphism, and supposed brain difference. However, in this perspective, biology fails to note the proper scale of things. Our physical characteristics are due to generations of evolution (Darwin, 1981). This evolution takes place when specific things in our environment turn on genes. Social reinforcement can be one of those triggers. A highly used example for gender differentiation is that of the hypothalamus, which controls our internal map.

While traveling, males in general make more use of cardinal directions: north, south, east and west, with use of distinct street names, and location markers (Dudchenko, 2010). Women on the other hand use landmarks and have a more fluid sense of direction. Biologists claim this sex difference is due to a biologically based sex difference in the hypothalamus. While it is the case that this differentiation exists and is biologically based, that does not fully explain why a sex difference exists. Men and women use and process directions differently because of this differentiated brain structure and function, their brains would not be structured or function this 
way if not for social/environmental needs for these functions, persisting over the course of our evolution (Darwin, 1981).

To illustrate, if Tom goes northeast and Sue goes up the hill next to the river, their basis for directions is rooted in their gendered socialized upbringing. Females in a hunter-gatherer community instill social interaction with detail-oriented communications. Since women would have been close together in a tribe, for their needs, directionally or otherwise, they would have utilized refined and specific detail, such as landmarks and paths, to convey directions to one another. Conversely, male socialization is based on the hunting needs of the hunter-gatherer society.

While on a hunt, communication between male humans has been simplified to make communicating at a distance easier. Generalized communication of directions or commands while hunting (like commands in modern sports) has reinforced gross simplified communication. The social factors are then passed on to our offspring, becoming a part of our biological inheritance. Thousands of years of evolution have distinguished the best directional awareness, for survival purposes, in human brains. Tom will go northeast because his social and biological instinct dictate simplified mental processing of direction. Sue will go up the hill near the river because of her innate utilization of details. This example illustrates how both nature and nurture work together to produce a gendered difference.

Discourses create a tug-of-war; one side is bolstering "nature," the other "nurture" when, in fact, both are very influential forces on one another. While both sides acknowledge the other's perspective, the two viewpoints are not well incorporated. It is difficult for researchers to focus on the relative accord of nature and nurture because most studies are designed to test specific 
hypotheses in order to accurately assess findings. Studies generalizing to a whole population may represent only a fraction of that population by sampling only certain age groups, not sampling enough minorities, and so on. The need for narrowed observations sometimes causes researchers to miss out on the bigger theoretical or practical picture.

To address methodological limitations, feminist researcher Janet Hyde performed a metaanalysis of various studies that compared the sexes across a wide variety of behaviors and characteristics (Hyde, 2005). She compiled the data from these narrowly focused studies to see what the cumulative data said about gender differences and similarities. The combined evidence shows support for Hyde's statement that males and females fail to differ in most areas of cognitive ability and personality (p. 590).

One useful example illustrated in Hyde's analysis comes from the comparison of emotion in the sexes. Across the studies reviewed, research has shown that, despite social stereotypes, the subjective experience of emotion fails to differ between males and females. However the general discourse believes that, “... women are often socialized (more so than men) to express emotions generally and express positive emotions" (Mikkelson et al., 2006, p. 431-432). Even though women and men experience emotion in the same way, we believe women to be the more "emotional" sex. These studies show, however, that many of our maintained ideas of sex and gender are not simply biologically based, but are also heavily influenced by social reinforcement. Reflecting on our evolutionary example, women's increased detail in communication may attribute to our perceptions of increased female emotionality.

Research designs that measure sex differences are use socially based stereotypes of sex and gender as their platform for test questions. Trying to determine if such stereotypes hold 
merit, researchers' findings can assist or break down gendered stereotypes, having positive or negative social effects. While some discourses, and the general population, stand on the side of sex differences, researchers are curious about sex/gender similarities. Research has established that "...males and females are similar on most, but not all, psychological variables. That is, men and women, as well as boys and girls are more alike than they are different. ...most psychological differences are in the close-to-zero or small range..." says psychologist Sandra Hyde (2005, p. 581).

While the emphasis on sex differences instead of sex similarities has shown much favor in the discourse, the cumulative data show otherwise. In fact, many of those with sex difference platforms do not account for social influence in their studies and refute social influence in their conclusions instead of looking at the full picture. Conversely, research on sexed/gendered similarities attempts to account for social and biological influences fairly equally. Additional bias enforced by peer review magnifies the presence of differences represented, as studies finding differences are more likely to be published than studies finding similarities (Denmark, Russo, Frieze, \& Sechzer, 1988).

Studies on sexed similarities include multiple acting factors on development between the sexes, and challenge the limitations of previous work, to eliminate bias. Hyde's meta-analysis organizes the results in an easily comparable format so that one can quickly get pertinent information from each study. The limitations of sample sizes, methods and other factors are also included so that each reader can judge the validity of the studies performed. Her conclusions show, ultimately, that men and women are not as dissimilar, or binary, as the common population assumes. 
Hyde's approach is very unlike what we have seen with Sax, who utilizes obscure research to support his sex difference platform. While his bias is not removed from his work there is still useful perspective to be gained. In Sax's dichotomized view, he states that the way we teach students frequently benefits one sex over the other depending on a given subject (2005). While social discourse generally dislikes the dichotomized view, Sax's argument is supported by social stereotypes in our culture.

To investigate the origins of one such stereotype, "girls are not good at math," researchers examined math and science aptitude of boys and girls (Spelke, 2005). Results showed that skill in math and science was not based on sex or gender, but on the number of math and science classes taken by a student. Historically, boys have been encouraged to take more math and science classes than girls. Despite this, in all but advanced mathematics courses, girls achieve higher grades in mathematics than boys through college. However, sex/gender disparity is great in math and science occupations. Factors such as biologically based, but learned differences in spatial ability, socialization by parents, teacher bias (as seen in Bandura's example of models), etc., account for mathematical and science disparity across the sexes. If biases were accounted for in our schools, Spelke's work suggests that sex differences would level out or disappear altogether. Between Sax's and Spelke's conclusions, both nature and nurture perspectives are represented in the scholarship.

Psychological discourse critique. In the early psychological discourse, we find that gender differences are often attributed to biological differences between the sexes. In the later discourse, we find a balance between biological and social influences. As a cumulative theoretical work, the discourse encompasses the two aspects. The earlier work by Freud focused on psycho-sexual elements of personality development. This perspective, with its biological and 
psychological framework, allowed for later work by theorists who focused on the psycho-social elements of personality development, grounded in social interaction.

Social influence is a powerful force on our ideas of sex and gender, but we are also born with an unlearned instinctual foundation of gender that should not be removed from the future analysis of this topic. For example, infants as young as three-months-old can tell their mother from their father and begin distinguishing other people by gender as a reflex (Quinn, Yahr, Kuhn, Slater, \& Pascalils, 2002). Instinctual knowledge and social reinforcement of gender roles build our gender schema. We are both biologically predispositioned to discriminate people by sex (as well as other features such as race, smell, height, etc.) and are psychologically stimulated with gender-discriminated information in our environment. Both nature and nurture perspectives are crucial to our definitions of sex and gender, and both perspectives are necessary if we are to reassess these definitions.

An additional critique of both discourses is that there exists limited research with intersexed and transgendered populations. Though these groups make up a small portion of the greater population, future research involving the influence of biological and social factors on intersexed/transgendered development would bring a wealth of knowledge to the sciences. We may gain additional insight into the influence of biological factors, such as brain function and hormones, as well as social factors, such as social stereotyping and interactions.

Research involving intersexed and transgendered populations may demonstrate differences in schema formation for these populations, showing more flexibility of current sex and gender concepts. Assuming non-normative populations experience sex and gender differently from normative populations, we might also find differences in gender identity development throughout the lifespan. Further research might eliminate some sex/gender 
confounds since these concepts are not as concrete in this population. Lastly, these studies may show results that aren't seen in normative populations, expanding our world view of human existence. This expansion helps to redefine our sex and gender systems and provide a more equitable voice for non-normative populations. Data collected from these rarer populations may later be included into meta-analyses (like that of Hyde's) giving a more complete perspective into analysis of scholarship.

In our discussion of sex and gender, the main point to take away is that our current definitions of sex and gender are too restrictive for the actual needs of our culture. The binary, two sex/two gender systems are not adequate representations of the population seen today or historically. As with anything that is restrictive or rigid, our sex and gender systems stifle the human experience, forcing everyone into one of two definitive categories. If one does not fit into the cookie cutter mold of male or female, feminine or masculine, then they are cast aside as deviant from the norm. This is a mistake perpetuated by our rigid definitions of sex and gender. Breaking down the restrictive binary model is dependent upon change and adaptation of our sex and gender systems.

In the psychological discourse, there is much room for interdisciplinary collaboration regarding gendered topics and a move toward more progressive non-binary structures. Neurological work is expanding as we build new technologies and learn more about the brain. Psychology is leaning in this neurological direction already, developing new disciplines such as interpersonal neurobiology. The discourse could build greatly upon social learning theories and gender schema theories by adapting the concept to neurological and feminist research, expanding the work. Cognitive study in this way can also be applied to theory regarding intersexed and transgendered development, which has been lacking in biological discourse, to expand our 
knowledge base. With the scope of the discourse expanded, the scholarship would better encompass the balance of nature and nurture.

One potential area for continued research may be found with gender schema theory and Bem's concept of gender aschematicity. While much research was conducted regarding cognitive processing of sex-typed information, little research has been conducted on aschematic child rearing (Bem, 1983). The examination of Bem's aschematic method is dependent upon biological and psychological scholarship. Biological and psychological theories define sex and gender across the history of the constructs, establishing a well-rounded perspective. With the full scope of these constructs in place, one can properly investigate the impact the concepts have on one another, and the power sex and gender have across social systems. With the full framework in place, we may now attempt to reassess and redefine these constructs. Reassessment of our sex and gender concepts may provide more equitable balance of power across the normative and non-normative populations as it would shed light on the issues of our current system. One method of reassessment is through the applications of gender aschematicity.

In general, Bem's concepts of gender aschematicity offer a method of "sex-typing prevention" that aims to eliminate gendered dichotomies from individual's lives. Though we do not really know how many aschematic individuals exist, there are a few reported cases. Children such as Sasha Laxton and Storm Witterick-Stocker have parents raising them without gender cues, as much as is possible within a gender binary system (Orr, 2012). While these cases are progressive steps toward Bem's aschematic lifestyle, these children are not raised completely free of gendered information. School, media, other children, etc., present gendered information and influence on these children's lives. In addition, while these cases may provide useful 
information they fail to provide a generalizable sample of gender aschematicity, or of what gender aschematic lives might be like.

For Bem's concepts to be applied, parents must start early, eliminating gendered input and blocking the formation of a gender schema. The aschematic process must start in infancy, before concepts of sex and gender are formed and, especially, before the child has achieved gender constancy (Bem, 1989). Once a child has formed a gender schema, children will continue to use gender as a way to process novel information. Continued exposure to gendered information, also known as sex-typing, helps to form and strengthen an individual's gender schema. Gender schema, like our previous example of animal schema, can fall into a larger category of social typologies. In the same way that we categorize information by gender, there are other social typologies we use to distinguish those around us (e.g., race and age).

When individuals accommodate novel information into existing schema, they build neural connections between the new information and existing information. For gender aschematicity to work, the new information must not be associated with gender. As such, the child will have to use other schema to process what would have otherwise been gendered information. Through lack of a gender schema, our brain must rely on other schema with relative social typologies. We must then categorize people not by their gender, but by other qualities. Aschematicity instills an automatic reassessment of sex and gender concepts since the gender aschematic individual is not likely to use gender as a means to discriminate between people. Aschematicity may also make an individual more accepting of diversity in general, as they would not view human differences as starkly as most of the population does. 
If one can become gender aschematic then lack of gender stereotyping and lack of sex typed restrictions may promote flexibility and tolerance among these individuals. Potential tolerance learned by aschematic individuals can be applied to other social typologies assuming they have multiple ways of processing information. Parents who are rearing children without gender cues are likely rearing them to be flexible or tolerant about individuals in all respects. Scholarship on this is hard to come by, however a few articles offer a helpful perspective.

Charlotte Patterson (1992) delves into many developmental aspects of children with gay parents. "Children of lesbian parents [see] themselves as more lovable and were seen by parents and teachers as more affectionate, more responsive, and more protective of younger children" (p.1032). According to Patterson, children of lesbian parents showed more acceptance of the people around them as a result of their upbringing. Some gay and lesbian parents, much like parents of gender aschematic children, attempt to eliminate gender stereotypes from their child's upbringing, fostering acceptance of diversity in their child. Though these children might still form gender schema, this is a strong example reflecting the potential benefits of gender aschematicity since both family types hold similar values surrounding gender.

Aschematicity might also cause individuals to be more accepting of non-normative populations in general because aschematic individuals would be more likely to have been exposed to greater diversity across a wide variety of sociocultural typologies. Intersexed and transgendered populations are likely accepted with less prejudice by aschematic persons than schematic persons. Reassessing our gender concepts, or eliminating gender binaries from our upbringing, would lead to more tolerance of diversity and increased general acceptance of people. Shifting our social values in this way offers better flexibility not just in gender but in other sociocultural typologies. 
By example, we can examine the sociocultural typology of race. Gender recognition and race recognition are innately present in us, as humans are predisposed to categorize others based on visual cues. Just as three-month-olds can distinguish between males and females, they can also distinguish between people of different races (Kelly et al., 2005). Because we use both gender and race to distinguish people, these social typologies process similarly in normative schema and carry similar weight socially. Gender aschematic children benefit from general increased acceptance and flexibility surrounding different genders because they do not see gender. The way they treat people in regard to gender may influence how they treat people within all social typologies. Though they may still form schema based on race, those around them promoting gender aschematicity are likely trying to provide them with greater diversity in their environments, thus may eliminate race based perspectives from the child's life as well. This combined with their fluidity of diversity (or their inability to see differences) in gender likely affects their overall interactions with other social distinctions.

If Bem's aschematic concept were implemented, gender aschematic child rearing would likely produce positive cognitive and social outcomes among participants. Not only would one's processing of information be free from gendered restrictions, but schema fluidity and diverse thinking may make gender aschematic children more adaptable to diversity throughout their lives. Since the experimental manipulation of children's environments for comparative analysis is impractical and unethical, the only opportunity to examine such an example is through naturalistic case studies. Future potential exists for shared aschematic-programs (perhaps Storm and Sasha's mothers begin a day care together) that might allow further observation of Bem's theory. 


\section{Conclusion}

In summation, being flexible about gender, race, or other distinguishing categories, would produce greater understanding within and between individuals, societies, and cultures. It would foster increased tolerance in the face of discrimination and help bolster interpersonal relations as well as interpersonal intelligence. In addition, dismantling our current constructs of gender with aschematicity, allows for more equitable representation of intersexed and transgendered persons. Future research needs to focus on intersexed and transgendered populations and breaking our current binary only sex/gender systems. Effective research would be better served by reassessing the current gender concepts, conducting further research using Bem's theories, and carefully designing studies that examine aschematic practices.

Potential limitations in this analysis are that, with the sheer volume of scholarship, it is impossible to explore the complete essence and structure of sex and gender within biological, psychological, sociological and historical realms. It is also difficult to examine Bem's gender aschematicity until future participants come forward and share information with researchers. This places a hold on aschematic benefit until more data can be collected. Additionally, further research will be necessary within the biological field, regarding intersexed populations. In all research done, only the normative populations have been considered. Within sexed-brain theories, additional work could be done comparing intersexed individuals to normative sexed males and females, as well as an analysis of intelligence-influence brain function. Comparison between the sexed-brain theory and intelligence-influence theory will support one and negate the other, creating a clear path for the future of the field. 
Limitations aside, having explored the scholarship of sex and gender, several issues have been assessed for their social and psychological impact on people. The nature of our binary only gender/sex systems, while comfortable to the lay population, is too restrictive for our society. There are far too many people who cannot fit into an "either/or" structure. The binary system, as it is, forces individuals to change who they are in order to meet the standards of others. Expansion into gender aschematic experience will grant additional knowledge, for multiple fields, into the inner workings of human beings and further show that relaxed notions of gender are beneficial as a whole.

\section{References}

Al-Sahab, B., Ardern, C. I., Hamadeh, M. J., \& Tamim, H. (2010). Age at menarche in Canada: Results from the National Longitudinal Survey of Children \& Youth. BMC Public Health, 10, 736.

American Psychological Association. (2006). Answers to your questions about individuals with intersex conditions. Washington, DC: American Psychiatric Publishing, Inc.

Bandura, A. (1969). Principles of behavior modification. New York: Holt, Rinehart and Winston.

Bandura, A. (1973). Aggression: A social learning analysis. Englewood Cliffs, N.J: Prentice-Hall. 
Barford, A., Dorling, D., Smith, G. D., \& Shaw, M. (2006). Life expectancy: Women now on top everywhere: During 2006, even in the poorest countries, women can expect to outlive men. British Medical Journal, 332, (7545), 808.

Bem, S. L. (1993). The lenses of gender: Transforming the debate on sexual inequality. New Haven: Yale University Press.

Bem, S. L. (1981). Gender schema theory: A cognitive account of sex typing. Psychological Review, 88, (4), 354-364.

Bem, S. L. (1983). Gender schema theory and its implications for child development: Raising gender-aschematic children in a gender-schematic society. Signs: Journal of Women in Culture and Society, 8, (4), 598-616.

Bem, S. L. (1989). Genital knowledge and gender constancy in preschool children. Child Development, 60, (3), 649-662.

Berne, E. (1968). A layman's guide to psychiatry and psychoanalysis. New York: Simon and Schuster.

Bigler, R. S. (1995). The role of classification skill in moderating environmental influences on children's gender stereotyping: A study of the functional use of gender in the classroom. Child Development, 66, (4), 1072-1087.

Blum, D. (1997). Sex on the brain: The biological differences between men and women. New York: Viking Press.

Bronfenbrenner, U. (1979). The ecology of human development: Experiments by nature and design. Cambridge, MA: Harvard University Press. 
Brush, S. G. (1991). Women in science and engineering. American Scientist, 79, 404-419.

Bussey, K., \& Bandura, A. (1999). Social cognitive theory of gender development and differentiation. Psychological Review, 106, (4), 676-713.

Callahan, G. N. (2009). Between XX and XY: Intersexuality and the myth of two sexes. Chicago, IL: Chicago Review Press.

Carothers, B. J., \& Reis, H. T. (2013). Men and women are from earth: Examining the latent structure of gender. Journal of Personality and Social Psychology, 104, (2), 385-407.

Chesler, P., Rothblum, E. D., \& Cole, E. (1995). Feminist foremothers in women's studies, psychology, and mental health. New York: Haworth Press.

Chodorow, N. (1978). The reproduction of mothering: Psychoanalysis and the sociology of gender. Berkeley: University of California Press.

Chodorow, N. (1989). Feminism and psychoanalytic theory. New Haven, CT: Yale University Press.

Colman, A. M. (2009). A dictionary of psychology. Oxford: Oxford University Press.

Darrah, J., Senthilselvan, A., \& Magillevans, J. (2009). Trajectories of serial motor scores of typically developing children: Implications for clinical decision making. Infant Behavior and Development, 32, (1), 72-78.

Darwin, C. (1981). The descent of man, and selection in relation to sex. Princeton, NJ: Princeton University Press. 
Denmark, F.L., Russo, N.F., Frieze, I.H., \& Sechzer, J.A. (1988). Guidelines for avoiding sexism in psychological research: A report of the ad hoc committee on nonsexist research. American Psychologist, 43, 582-585.

Deutsch, H. (1944). The psychology of women. New York: Grune \& Stratton.

Dudchenko, P. A. (2010). Why people get lost: The psychology and neuroscience of spatial cognition. New York: Oxford University Press.

Erikson, E. H. (1964). Inner and outer space: Reflections on womanhood. Daedalus, 93, (2), 582-606.

Erikson, E. H. (1978). Adulthood: Essays. New York: Norton.

Erikson, E. H. (1980). Identity and the life cycle. New York: Norton.

Fausto-Sterling, A. (2000). Sexing the body: Gender politics and the construction of sexuality. New York: Basic Books.

Federal Interagency Forum on Aging-Related Statistics (U.S.), \& National Center for Health Statistics (U.S.). (2012). Older Americans 2012: Key indicators of well-being. Washington, DC: Federal Interagency Forum on Aging Related Statistics.

Felder, R. M., Felder, G. N., Mauney, M., Hamrin, C. E. and Dietz, E. J. (1995), A longitudinal study of engineering student performance and retention. III. Gender differences in student performance and attitudes. Journal of Engineering Education. 84, 151-163.

Fine, C. (2011). Delusions of gender: How our minds, society, and neurosexism create difference. New York: W.W. Norton. 
Freud, S. (1930). Three contributions to the theory of sex. New York: Nervous and Mental Disease Pub. Co.

Freud, S. (1962). Three essays on the theory of sexuality. New York: Basic Books.

Eagly, A. H., Beall, A. E., \& Sternberg, R. J. (2004). The psychology of gender. New York: Guilford Press.

Gamble, S. (2001). The Routledge companion to feminism and postfeminism. London: Routledge.

Gardner, H. (1983). Frames of mind: The theory of multiple intelligences. New York: Basic Books.

Giedd, J. N., Blumenthal, J., Jeffries, N. O., Castellanos, F. X., Liu, H., Zijdenbos, A., Paus, T., Rapoport, J. L. (1999). Brain development during childhood and adolescence: A longitudinal MRI study. Nature Neuroscience, 2, 10.

Gur, R. C., Turetsky, B. I., Matsui, M., Yan, M., Bilker, W., Hughett, P., \& Gur, R. E. (1999). Sex differences in brain gray and white matter in healthy young adults: Correlations with cognitive performance. The Journal of Neuroscience, 19, (10), 4065-4072.

Halpern, D. F. (2012). Sex differences in cognitive abilities. New York: Psychology Press.

Hare-Mustin, R. T., \& Marecek, J. (1990). Making a difference: Psychology and the construction of gender. New Haven: Yale University Press. 
Hebb, D. O. (1949). The organization of behavior: A neuropsychological theory. New York: Wiley.

Horney, K. (1939). New ways in psychoanalysis. New York: W.W. Norton \& Co.

Hupp, J. M., Smith, J. L., Coleman, J. M., \& Brunell, A. B. (2010). That's a boy's toy: Gender-typed knowledge in toddlers as a function of mother's marital status. The Journal of Genetic Psychology, 171, (4), 385-401.

Hyde, J. S. (2005). The gender similarities hypothesis. The American Psychologist, 60, (6), 581-592.

Jung, C. G. (1915). The theory of psychoanalysis. New York: Journal of Nervous and Mental Disease Pub. Co.

Jung, C. G., \& Hinkle, M. B. M. (1916). Psychology of the unconscious: A study of the transformations and symbolisms of the libido, a contribution to the history of the evolution of thought. New York: Moffat, Yard and Co.

Kazdin, A. E. (2000). Encyclopedia of psychology. Washington, D.C: American Psychological Association.

Kelly, D. J., Quinn, P. C., Slater, A. M., Lee, K., Gibson, A., Smith, M., Ge, L., \& Pascalis, O. (2005). Three-month-olds, but not newborns, prefer own-race faces. Developmental Science, 8, (6), 31 .

Kohlberg, L. (1969). Stage and sequence: The cognitive-developmental approach to socialization. Chicago: Rand McNally. 
Kohlberg, L. (1987). Child psychology and childhood education: A cognitivedevelopmental view. New York: Longman.

Lansdell, H. (1964). Sex differences in hemispheric asymmetries of the human brain. Nature, 203, (4944), 550.

Lanfranco, F., Kamischke, A., Zitzmann, M., \& Nieschlag, E. (2004). Klinefelter's syndrome. Lancet, 364, 9430.

Lerner, R. M., \& Steinberg, L. D. (2009). Handbook of adolescent psychology. Hoboken, NJ: John Wiley \& Sons.

LeVay, S. (2011). Gay, straight, and the reason why: The science of sexual orientation. Oxford: Oxford University Press.

Lippa, R. A. (2005). Gender, nature, and nurture. New York: Lawrence Erlbaum Associates.

Marecek, J., \& Magnusson, Eva. (2012). Gender and culture in psychology. Cambridge University Press Textbooks.

Martin, C. L., \& Ruble, D. (2004). Children's search for gender cues: Cognitive perspectives on gender development. Current Directions in Psychological Science, 13, (2), 6770.

Martin, C. L., Ruble, D. N., \& Szkrybalo, J. (2002). Cognitive theories of early gender development. Psychological Bulletin, 128, (6), 903-933. 
Mikkelson, A. C., Farinelli, L., \& La, V. A. G. (2006). The influences of brain dominance and biological sex on emotional expressivity, sensitivity, and control. Communication Quarterly, 54, (4), 427-446.

Mtui, E., \& Gruener, G. (2006). Clinical neuroanatomy and neuroscience. Philadelphia, PA: Elsevier Saunders

Nadarajah, B., Brunstrom, J. E., Grutzendler, J., Wong, R. O., \& Pearlman, A. L. (2001). Two modes of radial migration in early development of the cerebral cortex. Nature Neuroscience, 4, (2), 143-150.

Ormrod, J. E. (1990). Human learning: Principles, theories, and educational applications. Columbus: Merrill Pub. Co.

Orr, C. E., \& Queen's University (2012). Bodies, deviancy, and socio-political Change: Judith Butler on intelligibility. Kingston.

Paris, B. J. (1994). Karen Horney: A psychoanalyst's search for self-understanding. New Haven: Yale University Press.

Patterson, C. J. (1992). Children of Lesbian and Gay Parents. Child Development, 63, 5, $1025-1042$.

Piaget, J. (1971). The theory of stages in cognitive development. Measurement and Piaget : Proceedings of the CTB/Mcgraw-Hill Conference on Ordinal Scales of Cognitive Development, 1-11.

Quinn, P. C., Yahr, J., Kuhn, A., Slater, A. M., \& Pascalils, O. (2002). Representation of the gender of human faces by infants: A preference for female. Perception, 31, (9), 1109-1121. 
Saladin, K. S. (2012). Anatomy \& physiology: The unity of form and function. New York, NY: McGraw-Hill.

Sax, L. (2005). Why gender matters: What parents and teachers need to know about the emerging science of sex differences. New York: Doubleday.

Skinner, B. F. (1938). The behavior of organisms: An experimental analysis. New York, London: D. Appleton-Century company, incorporated.

Spelke, E. S. (2005). Sex differences in intrinsic aptitude for mathematics and science? American Psychologist, 60, 9.

Sporns, O., Chialvo, D. R., Kaiser, M., \& Hilgetag, C. C. (2004). Organization, development and function of complex brain networks. Trends in Cognitive Sciences, 8, 9.

Sternberg, R. J. (1988). The triarchic mind: A new theory of human intelligence. New York: Viking.

Stevens, R. G., \& United States. (1995). The Declaration of Independence and the Constitution of the United States of America: The texts. Washington, DC: National Defense University Press.

Stiles, J., \& Jernigan, T. L. (2010). The basics of brain development. Neuropsychology Review, 20, (4), 327-348.

Sybert, V. (2004). Turner's syndrome. The New England Journal of Medicine, 351, 12.

Thompson, C. (1953). Towards a psychology of women. Pastoral Psychology, 4, 29-38. 
Visootsak, J (2009). Social function in multiple X and Y chromosome disorders: XXY, XYY, XXYY, XXXY. Developmental Disabilities Research Reviews (1940-5510), 15, (4), 328.

Watson, J. B. (1929). Behavior: An introduction to comparative psychology. New York: Holt, Rinehart and Winston.

Whitacre, C. C. (2001). Sex differences in autoimmune disease. Nature Immunology, 2, (9), 777-80.

Zucker, K. J., \& Bradley, S. J. (1995). Gender identity disorder and psychosexual problems in children and adolescents. New York: Guilford Press. 